\title{
Estimativa da divergência entre ecótipos de braquiária baseada em descritores quantitativos e qualitativos
}

\author{
Estimation of genetic divergence between braquiária ecotypes based on quantitative \\ and qualitative descriptors
}

\section{Francisco Eduardo Torres ${ }^{\mathrm{I}}$ Cacilda Borges do Valle ${ }^{\mathrm{II}}$ Beatriz Lempp $^{\mathrm{III}}$ Paulo Eduardo Teodoro ${ }^{\mathrm{I}}$ João Paulo Gonsiorkiewicz Rigon ${ }^{I V}$ Larissa Pereira Ribeiro ${ }^{I}$ Caio Cézar Guedes Corrêa Roque Apolinário Alves da Luz Júnior ${ }^{I}$}

\section{RESUMO}

O presente trabalho objetivou estimar a divergência genética entre ecótipos de Urochloa brizantha com base na análise de descritores quantitativos, qualitativos e sua análise conjunta a fim de selecionar os promissores para liberação como cultivares desta espécie. Oito ecótipos (B1, B2, B3, B4, B5, B6, $B 8$ ) e a cultivar 'Marandu'de U. brizantha foram implantados em piquetes, com $1000 \mathrm{~m}^{2}$ cada, em duas repetições. Foram avaliados cinco descritores quantitativos e dez qualitativos no periodo seco $e$ das águas. Os descritores quantitativos foram: área foliar, comprimento e largura das lâminas foliares, massa seca (MS) e proporção de lâmina foliar na MS. Os descritores qualitativos mensurados foram: resistência ao cisalhamento, volume de gás acumulado na fração rápida e lenta, proteina bruta, fibra em detergente neutro, fibra em detergente ácido, celulose, lignina em ácido sulfúrico, sílica e digestibilidade in vitro da matéria orgânica. Houve divergência genética entre os ecótipos de $\boldsymbol{U}$. brizantha, especialmente em relação aos descritores quantitativos. Com base nos agrupamentos dos descritores quantitativos, qualitativos e sua análise conjunta, o agrupamento contendo de B1, B3 e B5 com 'Marandu' podem resultar em ecótipos promissores de $\boldsymbol{U}$. brizantha.

Palavras-chave: análise conjunta, cultivar 'Marandu', descritores qualitativos, descritores quantitativos.

\section{ABSTRACT}

This study aimed to estimate the genetic divergence between Urochloa brizantha ecotypes based on quantitative, qualitative descriptors and their joint analysis to select the promising to release as cultivars of this species. Eight ecotypes (B1, B2, B3, B4, B5, B6, B8) and cultivar 'Marandu' of $\boldsymbol{U}$. brizantha were implanted into pickets with $1000 \mathrm{~m}^{2}$ each, with two repetitions. Five quantitative descriptors were evaluated [leaf area $(A L F)$, length and width of leaf blades (CLF and LLF, respectively), dry mass (MS), mass of dry matter (MMS) and proportion of leaf blade in MS (PLF)] in two forage samples, being a representative of rainfall, in February 2000, and another in the dry period, in August 2000. It was measured the qualitative descriptors: shear strength $(R C)$, volume of accumulated gas in fast and slow fraction ( $A$ and $B$, respectively), crude protein $(C P)$, neutral detergent fiber $(N D F)$, acid detergent fiber $(A D F)$, cellulose (CEL), lignin in sulfuric acid (LIG), silica (SIL) and in vitro digestibility of organic matter (IVOMD). There was considerable genetic divergence in $\boldsymbol{U}$. brizantha ecotypes, especially regarding to quantitative descriptors. Based on the groupings of quantitative, qualitative descriptors and their joint analysis, the grouping containing of B1, B3 and B5 with 'Marandu'can result in promising U. brizantha ecotypes.

Key words: joint analysis, 'Marandu', qualitative descriptors, quantitative descriptors.

\section{INTRODUÇÃO}

O programa de melhoramento genético de gramíneas forrageiras da espécie Urochloa brizantha (Hochst. ex A. Rich) da Embrapa Gado de Corte trabalha no desenvolvimento de cultivares forrageiras. Esse trabalho visa à redução da vulnerabilidade dos sistemas de produção de gado e que apresentem elevada produtividade, alto desempenho animal e baixa estacionalidade entre período seco e das águas,

IDepartamento de Fitotecnia, Faculdade de Agronomia, Universidade Estadual de Mato Grosso do Sul (UEMS), 79804-970, Aquidauana, MS, Brasil. E-mail: eduteodoro@hotmail.com.*Autor para correspondência.

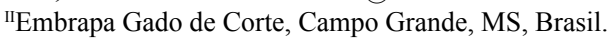

IIIPrograma de Pós-graduação em Agronomia, Departamento de Produção e Melhoramento Vegetal, Faculdade de Ciências Agrárias, Universidade Federal da Grande Dourados (UFGD), Dourados, MS, Brasil.

${ }^{\text {IV }}$ Programa de Pós-graduação em Agronomia, Departamento de Produção e Melhoramento Vegetal, Faculdade de Ciências Agronômicas (FCA), Universidade Estadual Paulista Júlio de Mesquita Filho (UNESP), Botucatu, SP, Brasil. Recebido 08.04.14 Aprovado 20.07.14 Devolvido pelo autor 03.11.14 CR-2014-0537.R2 
minimizando também a necessidade de abertura de novas áreas de cultivo.

$\mathrm{O}$ uso de técnicas multivariadas tem possibilitado estudos sobre divergência genética entre acessos de banco deste germoplasma. Análises multivariadas são em sua maioria baseadas em algoritmos, ou medidas de distância, que consideram simultaneamente inúmeras características e permite unificar múltiplas informações de um conjunto de caracteres (VILELA et al., 2008). Entre as técnicas disponíveis, os métodos aglomerativos são alguns dos mais utilizados, tendo como princípio reunir os genótipos em grupos de forma que haja homogeneidade dentro destes e heterogeneidade entre eles (MOHAMMADI \& PRASSANA, 2003). No entanto, esta metodologia é dependente do cálculo das medidas de dissimilaridade provenientes de inúmeras variáveis quantitativas e/ou qualitativas (CROSSA \& FRANCO, 2004).

A geração de um grande número de dados de diferentes categorias pode dificultar tanto a análise como a interpretação dos resultados de caracterização e avaliação do germoplasma, muitas vezes, resultando na incompleta distinção entre os ecótipos (ROCHA et al., 2010). Sendo assim, a análise conjunta das variáveis pode fornecer melhor indicação da potencialidade da variabilidade existente em bancos de germoplasma.

O algoritmo que permite a análise simultânea de dados quantitativos e qualitativos foi proposto por GOWER (1971), embora poucos trabalhos têm utilizado esta estratégia para quantificação da dissimilaridade genética, sendo relatados estudos na literatura com Brassica napus L. (RODRÍGUEZ et al., 2005), Triticum aestivum L. (VIEIRA et al., 2007) e Solanum lycopersicum H. Karst. (ROCHA et al., 2010).

Sob a hipótese de distinção e caracterização de ecótipos promissores no melhoramento genético de $\boldsymbol{U}$. brizantha, objetivou-se com o presente estudo estimar a divergência genética entre ecótipos desta espécie, com base na análise de descritores quantitativos, qualitativos e sua análise conjunta e indicar combinações promissoras para a produção de híbridos.

\section{MATERIAL E MÉTODOS}

O experimento foi conduzido na Embrapa Gado de Corte, em Campo Grande - MS, localizada a $20^{\circ} 28^{\prime}$ de latitude Sul e $55^{\circ} 40^{\prime}$ de longitude Oeste, com altitude média de $520 \mathrm{~m}$. O clima local, segundo a classificação de Köppen, é do tipo tropical chuvoso e de savana, subtipo AW, caracterizado por distribuição irregular de chuvas, com período seco e chuvoso bem definido.

O solo da área experimental foi classificado como Latossolo Vermelho-Escuro distrófico, segundo critérios da EMBRAPA (2013). No período experimental, a precipitação acumulada e a temperatura média no período das águas foram de $640 \mathrm{~mm}$ e $29,4^{\circ} \mathrm{C}$, respectivamente, e, no período seco, totalizaram $410 \mathrm{~mm}$ e $26,7^{\circ} \mathrm{C}$.

Oito ecótipos - B1, B2, B3, B4, B5, B6, B8 - e a cultivar 'Marandu' de Urochloa brizantha foram implantadas em 1994, em piquetes com $1000 \mathrm{~m}^{2}$ cada, em duas repetições, sendo os tratos culturais realizados conforme recomendações de HUGHES et al. (2000).

No período seco e das águas, quando a forragem apresentava crescimento acumulado de 42 dias, foram amostradas dez lâminas em três faixas transectas em cada repetição, coletandose sempre a segunda lâmina completamente expandida. As 30 amostras foram levadas para o laboratório, onde foram avaliados cinco descritores quantitativos [área foliar, comprimento e largura das lâminas foliares, massa seca (MS) e proporção de lâmina foliar na MS] e dez descritores qualitativos [resistência ao cisalhamento (RC); volume de gás, em $\mathrm{mL}$, acumulado na fração rápida e lenta (A e $\mathrm{B}$, respectivamente); proteína bruta ( $\mathrm{PB})$; fibra em detergente neutro (FDN); fibra em detergente ácido (FDA); celulose (CEL); lignina em ácido sulfúrico (LIG); sílica (SIL) e digestibilidade in vitro da matéria orgânica (DIVMO)].

Os descritores quantitativos e a RC (mediada em kgf com auxílio do equipamento WarnerBratzer) foram avaliados seguindo a metodologia proposta por HUGHES et al. (2000). As variáveis A e B foram mensuradas seguindo os procedimentos de SCHOFIELD et al. (1994). Os descritores PB, FDN, FDA, CEL, LIG, SIL e DIVMO foram determinados de acordo com a metodologia preconizada por GOERING \& VAN SOEST (1970).

Para os descritores quantitativos, estimouse a distância Euclidiana média padronizada (D), expressa por:

$$
d_{i j}=\sqrt{\frac{\sum_{k=1}^{n}\left(X_{i k}-X_{j k}\right)^{2}}{n}}
$$

em que $\mathrm{n}$ é o número de descritores mensurados; $X_{i k}$ é a observação no ecótipo $\mathrm{i}$ em referência à característica $\mathrm{k}$, e $\mathrm{X}_{\mathrm{ik}}$ é a observação no ecótipo j em referência à característica $\mathrm{k}$ (CRUZ et al., 2004). 
Para os descritores qualitativos, utilizou-se a distância de Cole-Rodgers $\left(\mathrm{D}^{2}\right)$ (COLE-RODGERS et al., 1997), conforme o modelo

$$
d_{i j}=\sum_{j=1}^{n} \frac{D_{j}}{C_{j} D_{j}}
$$

em que $\mathrm{C}_{\mathrm{j}}$ é o número de concordância entre os grupos para o j-ésimo descritor e $\mathrm{D}_{\mathrm{j}}$ é o número de discordância entre os grupos para o j-ésimo descritor. Para a análise conjunta dos descritores quantitativos e qualitativos, utilizou-se o algoritmo de Gower $\left(D^{3}\right)$ (GOWER, 1971), expresso por:

$$
S_{i j}=\frac{\sum_{k=1}^{p} W_{i j k} S_{i j k}}{\sum_{k=1}^{p} W_{i j k}}
$$

em que $\mathrm{K}$ é o número de descritores $(\mathrm{k}=1,2, \ldots$; $\mathrm{p}=$ número total de descritores avaliados); $\mathrm{i}$ e $\mathrm{j}$ são dois ecótipos quaisquer; $\mathrm{W}_{\mathrm{ijk}}$ é um peso dada a comparação ijk, atribuindo valor 1 para comparações válidas e valor 0 para comparações inválidas (quando o valor do descritor está ausente em um ou ambos indivíduos); $\mathrm{S}_{\mathrm{ijk}}$ é a contribuição do descritor $\mathrm{k}$ na similaridade entre os ecótipos i e j, possuindo valores entre 0 e 1.

Os agrupamentos hierárquicos das análises individuais e simultâneas a partir das matrizes de distância genética foram obtidos pelos métodos de UPGMA - Unweighted Pair Group Method with Arithmetic Mean (SOKAL \& ROHLF, 1962). As medidas de dissimilaridade e o método de agrupamento utilizado seguiram as recomendações de CRUZ et al. (2004). Todas as análises foram efetuadas com auxílio do software estatístico Genes (CRUZ, 2006).

\section{RESULTADOS E DISCUSSÃO}

Com base nos cinco descritores quantitativos, as menores distâncias foram observadas entre os ecótipos B3 e B6 $(\mathrm{D}=0,21)$ no período das águas, assim como entre os ecótipos B4 (Tabela 1) e B8 $(\mathrm{D}=0,40)$ no período seco, representando indivíduos genéticos semelhantes ou parentais. As combinações mais divergentes foram entre B5 e B8 $(D=2,70)$ no período das águas e entre $\mathrm{B} 4$ e $\mathrm{B} 5(\mathrm{D}=2,61)$ no período seco.

Em um dendrograma, uma grande mudança de nível indica a união de genótipos heterogêneos (BARROSO \& ARTES, 2003). Assim, utilizando-se $50 \%$ de similaridade como critério para definição dos grupos com base no método UPGMA (CRUZ et al., 2004), a partir dos descritores quantitativos avaliados, houve a formação de quatro e cinco grupos para os períodos das águas e seco, respectivamente (Figura 1 ).

Os ecótipos B4 e B8 constituíram um mesmo grupo em ambos os períodos de avaliação, reforçando a sugestão de similaridade entre si. Contudo, os outros grupos formados apresentaram oposições entre si, indicando comportamento distinto entre os demais ecótipos nos períodos avaliados. Isso indica que esses caracteres são mais complexos em função da resposta distinta dos ecótipos, diante das variações ambientais (RIGON et al., 2012). Estes resultados sugerem a possibilidade das linhagens extraídas destes ecótipos apresentarem divergência genética e, concomitantemente, heterose em combinações híbridas.

Baseado nos dez descritores qualitativos, no período das águas e seco, os ecótipos mais similares entre si foram $\mathrm{B} 2$ e B6 $\left(\mathrm{D}^{2}=0,32\right)$ e a cultivar 'Marandu' e B9 $\left(\mathrm{D}^{2}=0,25\right)$, respectivamente. Já B3 e $\mathrm{B} 5\left(\mathrm{D}^{2}=7,02\right)$, no período das águas, e B3 e a cultivar 'Marandu' $\left(\mathrm{D}^{2}=3,85\right)$, no seco, apresentaram maior dissimilaridade (Tabela 1). A dissimilaridade entre os ecótipos, estabelecida pelo método UPGMA, separou os ecótipos em três grupos para o período das águas e em quatro grupos para o período seco (Figura 2).

Os ecótipos B1 e B3 formaram um mesmo grupo, independente da época de avaliação, comportamento semelhante ao ecótipo B5, que também constituiu um único grupo. Isto permite inferir que as condições distintas entre as épocas de avaliação não influenciaram no comportamento qualitativo dos ecótipos. Com intuito de reduzir esforços e tornar o programa de melhoramento mais eficiente e econômico, a seleção de caracteres qualitativos em bancos de germoplasma, onde o número considerável de ecótipos inviabiliza a utilização de várias épocas de avaliação, pode ser realizada com base em dados experimentais de apenas uma estação do ano.

Utilizando o algoritmo de Gower para análise conjunta dos descritores quantitativos e qualitativos, identificaram-se os ecótipos B2 e B6 $\left(D^{3}=0,04\right)$ no período das águas e a cultivar 'Marandu' e B9 $\left(\mathrm{D}^{3}=0,14\right)$ no período seco como os mais similares, equiparando-se à classificação do método de Cole-Rodgers, utilizado para descritores qualitativos (Tabela 1). Os ecótipos B5 e B8 $\left(D^{3}=0,96\right)$ no período das águas e B4 e B5 no período seco $\left(\mathrm{D}^{3}=0,93\right)$ foram os mais divergentes entre si, sendo semelhante ao método da distância 
Tabela 1 - Estimativas da distância Euclidiana média padronizada (D) baseada na análise de cinco descritores quantitativos; distância de Cole-Rodgers $\left(\mathrm{D}^{2}\right)$ baseada na análise de dez descritores qualitativos; e distância de Gower $\left(\mathrm{D}^{3}\right)$ baseada na análise conjunta dos descritores quanti-qualitativos entre oito ecótipos e uma cultivar de Urochloa brizantha, avaliados no período das águas (diagonal superior) e seco (diagonal inferior).

\begin{tabular}{|c|c|c|c|c|c|c|c|c|c|}
\hline & B1 & B2 & B3 & B4 & B5 & B6 & Marandu & B8 & B9 \\
\hline B1 & & 0,67 & 0,56 & 1,17 & 1,77 & 0,77 & 1,43 & 1,24 & 0,46 \\
\hline B2 & 1,07 & & 0,33 & 1,59 & 1,20 & 0,37 & 1,48 & 1,55 & 0,39 \\
\hline B3 & 1,03 & 0,73 & & 1,48 & 1,48 & 0,21 & 1,69 & 1,33 & 0,43 \\
\hline B4 & 1,94 & 2,00 & 1,53 & & 2,64 & 1,78 & 1,73 & 0,78 & 1,21 \\
\hline B5 & 1,66 & 0,74 & 1,24 & 2,61 & & 1,31 & 1,84 & 2,70 & 1,50 \\
\hline B6 & 1,10 & 1,18 & 1,20 & 1,58 & 1,89 & & 1,81 & 1,62 & 0,67 \\
\hline Marandu & 0,67 & 0,74 & 0,44 & 1,77 & 1,25 & 1,24 & & 2,14 & 1,33 \\
\hline B8 & 1,81 & 1,75 & 1,24 & 0,40 & 2,32 & 1,52 & 1,53 & & 1,26 \\
\hline \multirow[t]{2}{*}{ B9 } & 1,04 & 0,94 & 0,66 & 1,80 & 1,45 & 1,01 & 0,74 & 1,59 & \\
\hline & & 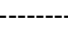 & . & istânc & le-Rod & 2)----- & 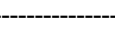 & 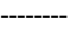 & ---- \\
\hline B1 & & 1,88 & 0,92 & 1,33 & 4,16 & 2,14 & 2,12 & 2,67 & 1,72 \\
\hline B2 & 2,70 & & 2,37 & 0,87 & 2,65 & 0,32 & 0,34 & 1,33 & 0,39 \\
\hline B3 & 0,40 & 2,65 & & 2,50 & 7,02 & 1,95 & 2,93 & 1,60 & 2,40 \\
\hline B4 & 2,85 & 0,91 & 2,63 & & 2,02 & 1,51 & 0,81 & 1,86 & 0,39 \\
\hline B5 & 2,37 & 2,05 & 3,02 & 2,87 & & 3,85 & 1,89 & 6,36 & 2,63 \\
\hline B6 & 2,52 & 1,24 & 2,52 & 3,04 & 1,93 & & 0,47 & 1,15 & 0,81 \\
\hline Marandu & 3,57 & 0,85 & 3,85 & 1,98 & 1,64 & 1,56 & & 1,92 & 0,53 \\
\hline B8 & 2,23 & 0,87 & 1,73 & 1,55 & 2,88 & 0,97 & 1,39 & & 1,25 \\
\hline B9 & 2,21 & 0,76 & 2,69 & 1,60 & 0,96 & 1,31 & 0,25 & 1,18 & \\
\hline ----- & & --- & $----D$ & $\operatorname{com} \mathrm{b}$ & lgoritn & ower (I & 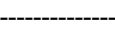 & ------- & ------ \\
\hline B1 & - & 0,41 & 0,28 & 0,61 & 0,47 & 0,58 & 0,84 & 0,47 & 0,30 \\
\hline B2 & 0,56 & - & 0,53 & 0,62 & 0,50 & 0,04 & 0,15 & 0,53 & 0,29 \\
\hline B3 & 0,42 & 0,70 & - & 0,61 & 0,27 & 0,35 & 0,81 & 0,26 & 0,28 \\
\hline B4 & 0,53 & 0,52 & 0,40 & - & 0,36 & 0,69 & 0,64 & 0,45 & 0,38 \\
\hline B5 & 0,19 & 0,45 & 0,37 & 0,93 & - & 0,55 & 0,91 & 0,96 & 0,42 \\
\hline B6 & 0,22 & 0,39 & 0,54 & 0,30 & 0,45 & - & 0,37 & 0,22 & 0,20 \\
\hline Marandu & 0,89 & 0,14 & 0,80 & 0,35 & 0,25 & 0,32 & - & 0,23 & 0,09 \\
\hline B8 & 0,21 & 0,20 & 0,36 & 0,38 & 0,41 & 0,55 & 0,62 & - & 0,54 \\
\hline B9 & 0,67 & 0,28 & 0,25 & 0,44 & 0,36 & 0,28 & 0,14 & 0,35 & - \\
\hline
\end{tabular}

Euclidiana média padronizada, utilizado para descritores qualitativos.

A dissimilaridade entre ecótipos, estabelecida pelo método UPGMA com base na análise conjunta de cinco descritores quantitativos e dez qualitativos, separou os ecótipos em cinco e sete grupos, respectivamente, para o período das águas e seco, evidenciando um maior critério na sua formação (Figura 3).

Isto evidencia uma grande contribuição dos descritores quantitativos e qualitativos, respectivamente, para a identificação de ecótipos mais divergentes e similares entre si. ROCHA et al. (2010) e MOURA et al. (2010), ao utilizarem o algoritmo de Gower na estimativa da divergência genética em germoplasma de pimenta verificaram maior eficiência na disjunção dos genótipos, quando foram utilizadas as variáveis qualitativas em comparação às quantitativas, discordando da presente pesquisa. Entretanto, o fato dos descritores quantitativos terem sido mais discriminantes não invalida a necessidade de utilizar descritores qualitativos nos estudos de divergência genética em $\boldsymbol{U}$. brizantha, pois estes caracteres, como o teor de proteína bruta e digestibilidade in vitro da matéria orgânica, por exemplo, são informações relevantes em programas de melhoramento desta espécie.

Com a análise conjunta dos dados, foi possível alocar os ecótipos B1 e B3 em um mesmo grupo, independente da época de avaliação, 

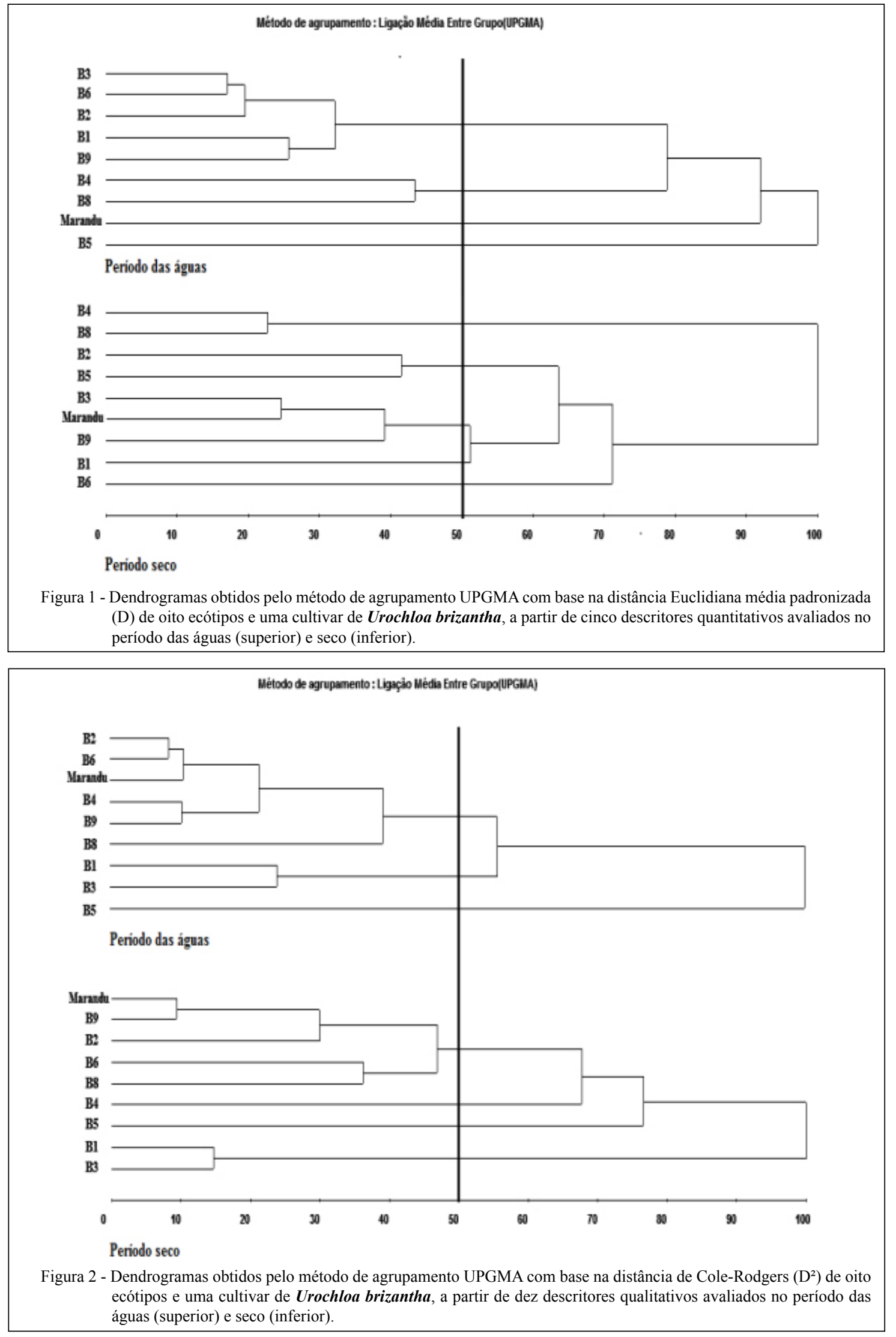

Ciência Rural, v.45, n.3, mar, 2015. 


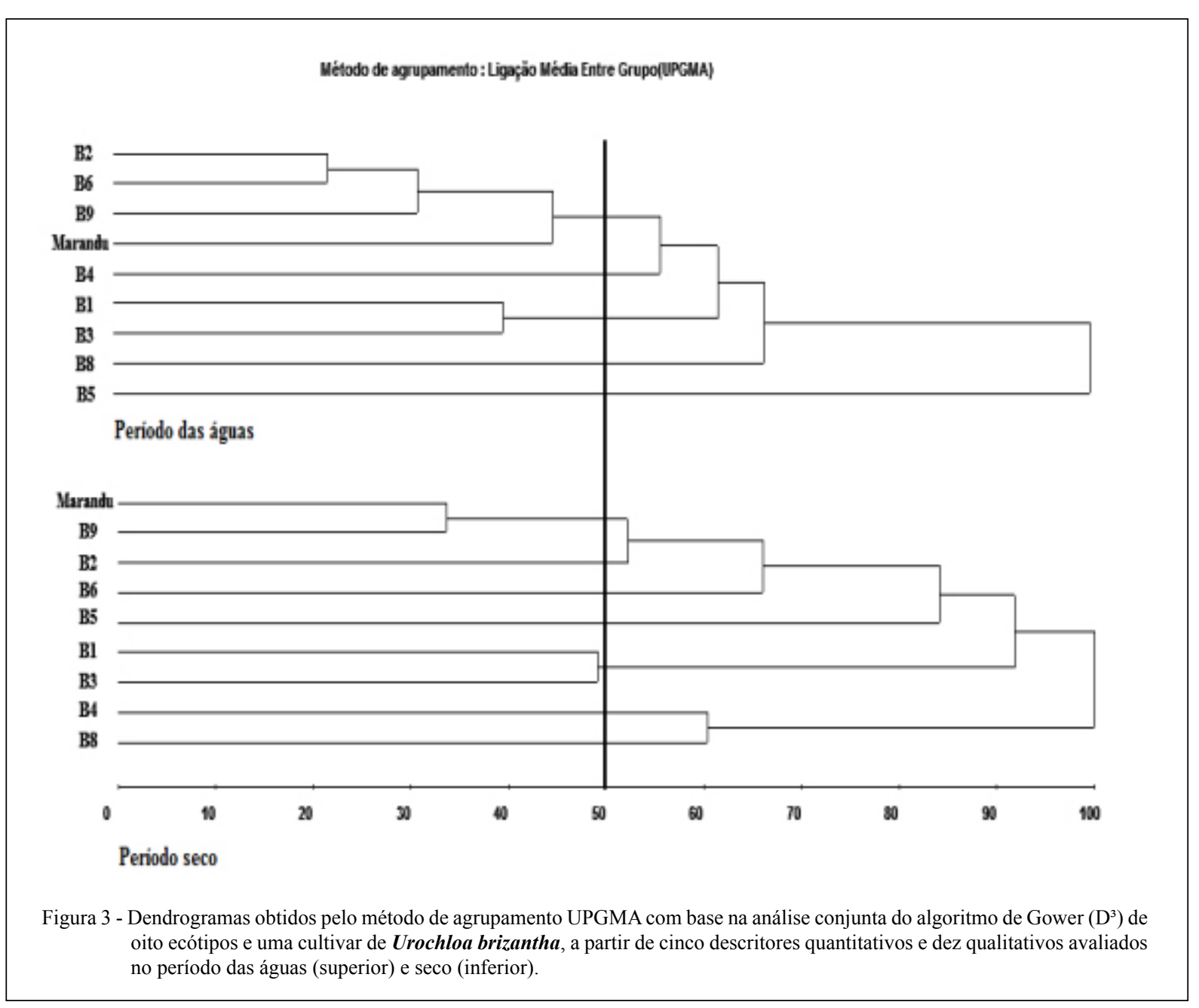

comportamento semelhante aos ecótipos B4, B5 e B8, que também constituíram grupos isolados em ambos os períodos. Com base nos agrupamentos dos descritores quantitativos, qualitativos e sua análise conjunta, os ecótipos B2 e B9 são os mais similares à cultivar 'Marandu', amplamente cultivada no Brasil. Em contrapartida, os mais divergentes foram os ecótipos B1, B3 e B5, possibilitando explorar a heterose pelo cruzamento entre si.

A grande maioria das pesquisas de caracterização e avaliação de germoplasma, em geral, utiliza-se de descritores qualitativos e quantitativos separadamente, uma vez que estes últimos são analisados apenas por estatística descritiva. Isso pode segmentar as inferências e conclusões sobre a divergência genética entre os ecótipos, limitando, muitas vezes, sua utilização posterior, por exemplo, em programas de melhoramento genético. A análise conjunta de dados de natureza qualitativa e quantitativa através do algoritmo de Gower pode propiciar melhor compreensão das características consideradas e, principalmente, conclusões mais criteriosas e eficazes do ponto de vista estatístico sobre o relacionamento genético entre os ecótipos estudados.

\section{CONCLUSÃO}

Houve divergência genética entre os ecótipos de $\boldsymbol{U}$. brizantha, sobretudo em relação aos descritores quantitativos. Com base nos agrupamentos dos descritores quantitativos, qualitativos e sua análise conjunta, o agrupamento contendo de B1, B3 e B5 com a cultivar 'Marandu' pode resultar em genótipos promissores de $\boldsymbol{U}$. brizantha.

\section{REFERÊNCIAS}

BARROSO, L.P.; ARTES, R. Análise multivariada. Lavras: UFLA, 2003. 151p.

Ciência Rural, v.45, n.3, mar, 2015. 
COLE-RODGERS, P. et al. A novel statistical approach to analyze genetic resource evaluations using Capsicum as an example. Crop Science, v.37, p.1000-1002, 1997. Disponível em: $<$ http://dx.doi. org/10.2135/cropsci1997.0011183X003700030050x>. Acesso em: 21 nov. 2013. doi: 10.2135/cropsci1997.0011183X0037000 30050x.

CROSSA, J.; FRANCO, J. Statistical methods for classifying genotypes. Euphytica, v.137, n.1, p.19-37, 2004. Disponível em: $<$ http://dx.doi.org/10.1023/B:EUPH.0000040500.86428.e8>. Acesso em: 22 nov. 2013. doi: 10.1023/B:EUPH.0000040500.86428.e8.

CRUZ, C.D. Programa genes: biometria. Viçosa: UFV, 2006. 382p.

CRUZ, C.D. et al. Modelos biométricos aplicados ao melhoramento genético. 3.ed. Viçosa: UFV, 2004. 480p.

EMBRAPA. Sistema brasileiro de classificação de solos. Brasília: Embrapa-SPI; Rio de Janeiro: Embrapa-Solos, 2013. $353 p$.

GOERING, H.K.; VAN SOEST, P. Forage fiber analyses (Apparatus, reagents, procedures, and some applications). Agricultural Hand Tools in Emergencies, v.379, p.1-20, 1970.

GOWER, J.C. A general coefficient of similarity and some of its properties. Biometrics, v.27, n.4, p.857-874, 1971.

HUGHES, N.R.G. et al. Shearing strength as additional selection criterion for quality in Brachiaria pasture ecotypes. Journal of Agricultural Science, v.135, p.123-130, 2000.

MOHAMMADI, S.A.; PRASANNA, B.M. Analysis of genetic diversity in crop plants-salient statistical tools and considerations. Crop Science, v.43, n.4, p.1235-1248, 2003. Disponível em: $<$ http://dx.doi.org/10.2135/cropsci2003.1235>. Acesso em: 14 dez. 2013. doi:10.2135/cropsci2003.1235.

MOURA, M.C.C.L. et al. Algoritmo de Gower na estimativa da divergência genética em germoplasma de pimenta. Horticultura
Brasileira, v.28, p.155-161, 2010. Disponível em: <http://dx.doi. org/10.1590/S0102-05362010000200003>. Acesso em: $21 \mathrm{dez}$. 2013. doi: 10.1590/S0102-05362010000200003.

RIGON, J.P.G. et al. Dissimilaridade genética de girassol por meio de caracteres quantitativos. Ciência Rural, v.42, n.11, p.19541959, 2012. Disponível em: <http://dx.doi.org/10.1590/S0103$84782012001100008>$. Acesso em: 02 jan. 2014. doi: 10.1590/ S0103-84782012001100008.

ROCHA, M.C. et al. Uso do algoritmo de Gower na determinação da divergência genética entre acessos de tomateiro do grupo cereja. Acta Scientiarum Agronomy, v.32, n.3, p.423-431, 2010. Disponível em: <http://dx.doi.org/10.4025/actasciagron. v32i3.4888>. Acesso em: 04 jan. 2014. doi:10.4025/actasciagron. v32i3.4888.

RODRÍGUEZ, V.M et al. The nabicol: a horticultural crop in northwestern Spain. Euphytica, v.142, n.1, p.237-246, 2005.

SCHOFIELD, P. et al. Kinetcs of fiber digestion from in vitro gas production. Journal of Animal Science, v.72, n.11, p.90-291, 1994

SOKAL, R.R.; ROHLF, F.J. The comparison of dendrograms by objective methods. Taxon, v.11, p.33-40, 1962.

VIEIRA, E.A. et al. Association between genetic distances in wheat (Triticum aestivum L.) as estimated by AFLP and morphological markers. Genetics and Molecular Biology, v.30, n.2, p.392-399, 2007. Disponível em: <http://dx.doi.org/10.1590/ S1415-47572007000300016>. Acesso em: 10 jan. 2014 . doi: $10.1590 / \mathrm{S} 1415-47572007000300016$

VILELA, F.O. et al. Effect of recurrent selection on the genetic variability of the UNB-2U popcorn population using RAPD markers. Acta Scientiarum Agronomy, v.30, n.1, p.25-30, 2008. Disponível em: <http://dx.doi.org/10.4025/actasciagron. v30i1.1123>. Acesso em: 16 jan. 2014. doi: 10.4025/actasciagron. v30i1.1123. 